\title{
PENILAIAN KEPUASAN PENGHUNI APARTEMEN MEDITERANIA GARDEN RESIDENCE 2 DENGAN METODE IMPORTANCE PERFORMANCE ANALYSIS ( IPA ) ( STUDI KASUS di PT PRIMA BUANA INTERNUSA )
}

\author{
Popy Yuliarty ${ }^{1)}$, Fahrizal Yahya ${ }^{2)}$ \\ 1 Prodi Teknik Industri, Universitas Mercu Buana, jl.Meruya Selatan No.1 Kembangan Jakbar \\ 2 Prodi Teknik Industri, Universitas Mercu Buana, jl.Meruya Selatan No.1 Kembangan Jakbar
}

\begin{abstract}
Abstrak, Seiring berjalannya waktu, bisnis property saat ini dirasa sangat menjanjikan dan mengundang para developer atau pengembang untuk mendalami dan lebih serius di bidang ini. Dan salah satu investasi di bidang property adalah apartemen.Selain fasilitas yang diberikan tidak jarang para pengembang apartemen menarik minat calon pembeli dan penghuni dengan janji memberikan kualitas pelayanan yang cepat dan memuaskan penghuni. Beberapa fasilitas yang diberikan dan pelayanan yang diberikan diharapkan dapat memberikan kepuasan dan kenyamanan penghuni akan kualitas pelayanan dari pihak penglola apartemen. Tujuan penelitian ini untuk mengetahui tingkat kepuasan pelayanan service dan preventive yang di berikan pengelola Apartemen Mediterania Garden Residence 2 kepada penghuni dengan metode Importanca Performance Analysis (IPA). Hasil dari penelitian ini adalah atribut pelayanan yang menjadi prioritas improvement dengan atribut yang berada di zona kuadran A dan Kuadran C, adalah : pelayanan customer service yang cepat, pembayaran tagihan listrik, air dan maintenance di bagian keuangan selalu update, lahan parkir cukup luas dan tertata rapi, kemudahan penghuni dalam memperoleh berbagai informasi, kebersihan lingkungan area apartemen yang terjaga
\end{abstract}

Kata Kunci : Kepuasan Penghuni, Apartemen, Atribut, IPA

\section{PENDAHULUAN}

Padatnya populasi baik di dunia ataupun di Indonesia menandakan dan membuktikan bahwa perkembangan penduduk saat ini terus mengalami pertumbuhan yang pesat. Indonesia khususnya di wilayah provinsi DKI Jakarta kepadatan penduduk sekarang ini sudah mencapai 10,37 juta jiwa (Sumber : Badan Pusat Statistik Provinsi DKI Jakarta Tahun 2017), dan akan terus meningkat dari tahun ke tahun. Salah satu faktor adalah di dorong oleh angka kelahiran yang lebih tinggi dibandingkan angka kematian di Indonesia. Hasilnya populasi meningkat dan padat sangat berpengaruh kepada kebutuhan manusia terutama kebutuhan manusia akan suatu tempat tinggal yang merupakan kebutuhan utama. Lahan untuk tempat tinggal yang tersedia jumlahnya sangat terbatas khususnya di kota kota besar seperti Jakarta, Surabaya, Medan. Sementara penduduk yang padat memaksa pemerintah untuk membenahi system tata kota agar masyarakat yang belum mendapatkan tempat tinggal yang layak dan untuk tempat tinggal yang belum layak dapat diberikan suatu hunian yang memadai atau setidaknya agar semakin sedikit warga negara Indonesia yang tinggal di tempat - tempat liar dan tidak layak huni. Oleh karena itu, solusi dan jawaban dari pemerintah adalah dengan mendirikan rumah susun atau apartemen kelas menengah ke bawah. Hal ini karena tidak memungkinkan lagi untuk mendirikan rumah yang langsung menempel pada tanah dengan lahan yang sangat terbatas di Jakarta.

Seiring berjalannya waktu, bisnis property saat ini dirasa sangat menjanjikan dan mengundang para pengembang untuk mendalami dan lebih serius di bidang ini. Dan salah satu investasi di bidang property adalah apartemen. Selain fasilitas yang diberikan tidak jarang para pengembang apartemen menarik minat calon pembeli dan penghuni dengan janji memberikan kualitas pelayanan yang cepat dan memuaskan penghuni. Beberapa fasilitas yang diberikan dan pelayanan yang diberikan diharapkan dapat memberikan kepuasan dan kenyamanan penghuni akan kualitas pelayanan dari pihak penglola apartemen. Apartemen Mediterania Garden Residence 2 sebagai salah satu pemukiman ingin memberikan pelayanan 
terbaik kepada para penghuninya. Penelutian ini bertujuan untuk mengetahui kepuasan penghuni apartemen hadap pelayanan yang telah diberikan oleh pihak pengelola.

\section{METODE PENELITIAN}

Metode diartikan sebagai cara yang tepat, kemudian penelitian adalah kegiatan ilmiah untuk memperoleh pengetahuan yang benar tentang suatu masalah. Didalam penelitian ini menggunakan model kuantitatif dan model kualitatif atau dengan kata lain model campuran. Flowchart penelitian ini dapat dilihat pada gambar 1 berikut ini :

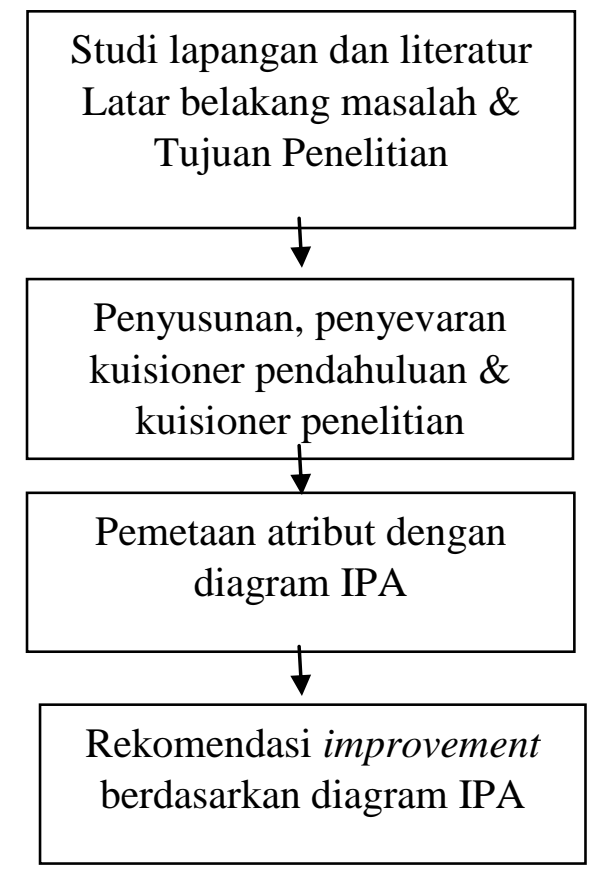

Gambar 1. Flowchart penelitian

\section{HASIL DAN PEMBAHASAN}

Untuk pengumpulan data, maka dilakukan penyebaran kuisioner pendahuluan, kemudian dilakukan uji validasi dan uji reliabilitas, kemudian penyebaran kuisioner dilakukan dengan sampling kepada 150 responden dalam hal ini yaitu penghuni aparteman.

Hasil perhitungan servqual Gap 1 dapat dilihat pada tabel 1 berikut ini : 
Tabel 1. Nilai Gap 1

\begin{tabular}{|c|c|c|c|c|c|}
\hline No. & \multicolumn{2}{|r|}{ Atribut } & \multirow{2}{*}{$\begin{array}{c}\begin{array}{c}\text { Skor rata- } \\
\text { rata persepsi } \\
\text { manajemen }\end{array} \\
3.20 \\
\end{array}$} & \multirow{2}{*}{ 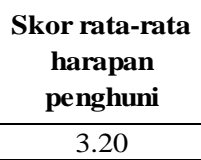 } & \multirow{2}{*}{$\begin{array}{c}\text { Gap 1 } \\
\text { (Servqual Score) } \\
0.00\end{array}$} \\
\hline \multirow{7}{*}{ Tangible } & a. & Customer Service & & & \\
\hline & b. & Receptionist & 3.20 & 3.10 & 0.10 \\
\hline & c. & Security & 3.20 & 3.10 & 0.10 \\
\hline & d. & Engineering & 3.30 & 3.10 & 0.20 \\
\hline & e. & Finance & 3.10 & 2.90 & 0.20 \\
\hline & f. & Housekeeping & 3.20 & 3.00 & 0.20 \\
\hline & g. & Parkir & 3.10 & 3.10 & 0.00 \\
\hline \multirow{7}{*}{ Reliability } & a. & Customer Service & 3.30 & 3.00 & 0.30 \\
\hline & b. & Receptionist & 3.00 & 3.00 & 0.00 \\
\hline & c. & Security & 3.10 & 2.90 & 0.20 \\
\hline & d. & Engineering & 3.20 & 3.10 & 0.10 \\
\hline & e. & Finance & 3.10 & 3.00 & 0.10 \\
\hline & f. & Housekeeping & 3.30 & 3.00 & 0.30 \\
\hline & g. & Parkir & 2.90 & 2.90 & 0.00 \\
\hline \multirow{7}{*}{ Responsivenes } & a. & Kolam Renang & 2.90 & 2.90 & 0.00 \\
\hline & b. & Parkir & 2.90 & 2.90 & 0.00 \\
\hline & c. & Lobby & 2.80 & 2.80 & 0.00 \\
\hline & d. & Lift & 3.30 & 3.00 & 0.30 \\
\hline & e. & Tenis & 3.30 & 3.00 & 0.30 \\
\hline & f. & Children Play Ground & 3.10 & 3.00 & 0.10 \\
\hline & g. & Koridor & 3.20 & 3.10 & 0.10 \\
\hline \multirow{6}{*}{ Emphaty } & a. & Kebersihan & 3.10 & 3.00 & 0.10 \\
\hline & b. & Penerangan & 3.30 & 3.10 & 0.20 \\
\hline & c. & Penghijauan & 3.20 & 3.10 & 0.10 \\
\hline & d. & Signage / petunjuk arah & 3.10 & 3.00 & 0.10 \\
\hline & e. & Keamanan & 3.20 & 3.10 & 0.10 \\
\hline & f. & Kemudahan informasi & 3.10 & 3.00 & 0.10 \\
\hline \multicolumn{5}{|c|}{ Gab Maksimum } & 0.30 \\
\hline \multicolumn{5}{|c|}{ Gab Minimum } & 0.00 \\
\hline
\end{tabular}

Sumber : Pengolahan data

Dari Tabel diatas dapat dilihat bahwa seluruh dimensi bernilai positif. Artinya pada keseluruhan dimensi kualitas pelayanan, manajemen apartemen mediterania gardence 2 mempersepsikan harapan penghuni lebih tinggi daripada harapan manajeben itu sendiri. Sehingga pada GAP ini kesenjangan tidak terjadi.

Important Performance Analysis atau Analisis Tingkat Harapan Kepuasan Pelanggan dilakukan dengan menghitung skor total kinerja pelayanan dan kepentingan/harapan Penghuni Apartemen Mediterania Garden Residence 2. Selanjutnya dilakukan perhitungan nilai $X$ (rata-rata skor kinerja) dan Y (rata-rata skor kepentingan) yang akan dipetakan dalam diagram kartesius dengan software SPSS 17.0 for Windows. Diagram Hasil Penilaian Res ponden Dengan Metode IPA dapat dilihat pada gambar 2 berikut ini 


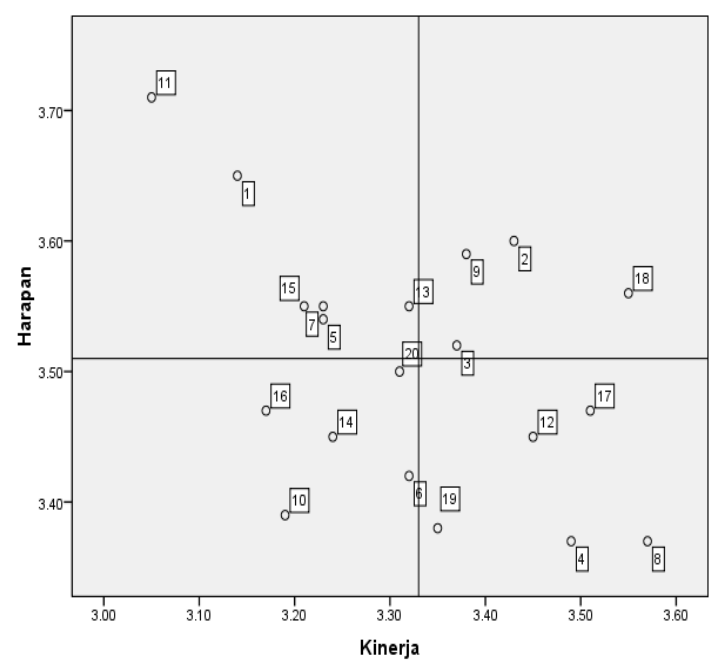

Gambar 2. Diagram kartesius penilaian responden

Table 2. Skor Atribut

\begin{tabular}{|c|l|c|c|c|}
\hline $\begin{array}{c}\text { No } \\
\text { atribut }\end{array}$ & \multicolumn{1}{|c|}{ Atribut } & Skor & $\begin{array}{c}\text { Kinerja Kulitas } \\
\text { Pelayanan }\end{array}$ & $\begin{array}{c}\text { Letak } \\
\text { Kuadran }\end{array}$ \\
\hline 1 & Customer Service & 86.11 & Sangat Baik & A \\
\hline 2 & Receptionist & 95.37 & Sangat Baik & B \\
\hline 3 & Security & 95.64 & Sangat Baik & B \\
\hline 4 & Engineering & 103.56 & Sangat Baik & D \\
\hline 5 & Finance & 91.34 & Sangat Baik & A \\
\hline 6 & Housekeeping & 97.08 & Sangat Baik & C \\
\hline 7 & Parkir & 91.17 & Sangat Baik & A \\
\hline 8 & Kolam Renang & 105.73 & Sangat Baik & D \\
\hline 9 & Parkir & 94.06 & Sangat Baik & B \\
\hline 10 & Lobby & 94.11 & Sangat Baik & C \\
\hline 11 & Lift & 82.05 & Sangat Baik & A \\
\hline 12 & Tenis & 100.00 & Sangat Baik & D \\
\hline 13 & Children Play Ground & 93.43 & Sangat Baik & A \\
\hline 14 & Koridor & 94.00 & Sangat Baik & C \\
\hline 15 & Kebersihan & 90.43 & Sangat Baik & A \\
\hline 16 & Penerangan & 91.17 & Sangat Baik & C \\
\hline 17 & Penghijauan & 101.35 & Sangat Baik & D \\
\hline 18 & Signage/ petunjuk arah & 99.81 & Sangat Baik & B \\
\hline 19 & Keamanan & 99.01 & Sangat Baik & D \\
\hline 20 & Kemudahan informasi & 94.48 & Sangat Baik & C \\
\hline & & & & \\
\hline
\end{tabular}

Kriteria Penilaian Keseluruhan :

$0.81-1.00=$ Sangat Baik

$0.66-0.80=$ Baik

$0.51-0.65=$ Cukup Baik

$0.35-0.50=$ Kurang Baik

$0.00-0.34=$ Sangat Tidak

Sumber : Pengolahan data 
Berdasarkan gambar kartesius diatas (gambar 2 ), diartikan sebagai berikut :

1. kuadran I (Concentrate These) Ini adalah wilayah yang memuat faktor-faktor yang dianggap penting oleh pelanggan, tetapi pada kenyataannya faktor-faktor ini belum sesuai dengan harapan pelanggan (tingkat kepuasan yang diperoleh masih rendah). Variabel-variabel yang masuk dalam kuadran ini harus ditingkatkan. Yang termasuk kuadran 1 adalah atribut :

(1) Pelayanan customer service di Apartemen Mediterania Garden Residence 2 cepat

(5) Pembayaran tagihan Listrik , Air dan Maintenance di Finance selalu Update

(7) Lahan untuk parkir kendaraan bermotor nyaman dan tertata rapi

(11) Perawatan lift dilakukan berkala , sehingga Lift aman untuk digunakan

(13) Tempat bermain anak atau Children Play Ground di buat menarik dan nyaman

(15) Lingkungan area Apartemen Mediterania Garden Residence 2 bersih dan harum

2. Kuadran II (Keep Up The Good Work) Ini adalah wilayah yang memuat faktor-faktor yang dianggap penting oleh pelanggan, dan faktor-faktor yang dianggap pelanggan sudah sesuai dengan yang dirasakannya sehingga tingkat kepuasannya relatif lebih tinggi. Variabel-variabel yang masuk dalam kuadran ini harus tetap dipertahankan karena semua variabel ini menjadikan produk atau jasa unggul di mata pelanggan. Yang termasuk kuadran II adalah atribut :

(2) Receptionist melayani dengan ramah dan jelas ketika ada customer

(3) Security menjaga lingkungan apartemen dengan ketat

(9) Lahan untuk perkir kendaraan mobil luas dan rapi

(18) Signage atau petunjuk arah sangat jelas dan tertampang disetiap sudut area

3. Kuadran III (Low Priority) Ini adalah wilayah yang memuat faktor-faktor yang dianggap kurang penting oleh pelanggan, dan pada kenyatannya kinerjanya tidak terlalu istimewa. Peningkatan variabelvariabel yang termasuk dalam kuadran ini dapat dipertimbangkan kembali karena pengaruhnya terhadap manfaat yang dirasakan oleh pelanggan sangat kecil. Yang termasuk kuadran III adalah atribut :

(6) Houskeeping membersihkan area apartemen dengan teliti

(10) Lobby apartemen menyediakan ruang tunggu bagi para tamu atau pengunjung

(14) Koridor di area unit terlihat bersih dan harum

(16) Penerangan gedung apartemen cukup terang ketika malam hari

(20) Informasi bagi para penghuni cukup mudah karena banyak di sediakan papan informasi

4. Kuadran IV (Possible Overkill) Ini adalah wilayah yang memuat faktror-faktor yang dianggap kurang penting oleh pelanggan, dan dirasakan terlalu berlebihan. Variabelvariabel yang termasuk dalam kuadran ini dapat dikurangi agar perusahaan dapat menghemat biaya. Yang termasuk kuadran IV adalah atribut :

(4) Engineering melakukan maintenance sesuai schedule dan perbaikan secara baik.

(8) Terdapat macam jenis kolam renang di apartmen ynag cukup lebar dan airnya jernih

(12) Lapangan tenis tersedia dengan bagus bagi para penghuni

(17) area lingkungan apartemen penghijauan dengan menaruh berbagai jenis macam tanaman

(19) keamanan di setiap sudut dengan meletakkan CCTV

\section{KESIMPULAN DAN SARAN}

1. Berdasarkan analisis IPA, terdapat beberapa atribut yang paling penting namun juga kinerjanya tidak sesuai harapan penghuni. Salah satu prioritas atribut dengan nilai kinerjanya paling tidak memuaskan adalah "Keamanan Apartemen". Untuk meningkatkan kinerja pada atribut ini, dilakukan usaha-usaha antara lain : penambahan perseni1 keamanan atau security di lapangar 41 menambahkan Cctv dilokasi yang jaring terpantau oleh petugas keamanan, memperketat akses jalur keluar masuk penghuni dan kendaraan penghuni di lingkungan apartemen. 
2. Atribut pelayanan yang menjadi prioritas improvement berdasarkan perhitungan Importance Performance Analysis (IPA) dengan atribut yang berada di zona kuadran A dan Kuadran C, adalah sebagai berikut :
a. Pelayanan Customer Service yang cepat.
b. Pembayaran tagihan Listrik, Air dan Maintenance di Finance selalu Update.
c. Lahan parker di apartemen Mediterania Garden Residence 2 cukup luas dan tertata rapi.
d. Kemudahan Penghuni dalam memperoleh berbagai informasi
e. Kebersihan lingkungan area apartemen yang terjaga

\section{DAFTAR PUSTAKA}

Arikunto, R.A. 2006 .Prosedur penelitian suatu pendekatan praktik. Jakarta:Rineka Cipta

Garvin, D. 2001. Managing Quality, di dalam Nasution, M.N. . Manajemen Alutu Terpadu (Total Quality Management).Jakarta:Ghalia Indonesia
Ghozali, .I. 2013. Aplikasi Analisis Multivariate dengan Program SPSS Edisi Ketujuh. Semarang : Badan Penerbit Universitas Diponegoro.

Istijanto. 2005. Riset Sumber Daya Manusia, Jakarta : PT. Gramedia Pustaka Utama.

Kotler. P. \& Kevin. L. K. 2009. Manajemen Pemasaran. Jilid Satu. Alih Bahasa oleh Bob Sabran. Edisi 13. Jakarta: Erlangga

Martilla. J.A. \& James, J.C. 1977. Importanceperformance analysis. Journal of Marketing, Vol. 41 No. 1, pp. 77-9

John. C.M. \& Michael .M. 2002, Perilaku Konsumen (Jilid 1), Jakarta : Erlangga.

Sugiyono. 2007, Statistik Untuk Penelitian, Bandung: CV Afabeta.

Supranto J, 2001. Pengukuran Tingkat Kepuasan Pelanggan, Jakarta : Rineka Cipta.

Sutrisno .H. 1997. Metode Penelitian. Yogyakarta: UGM Press.

Zeithaml. Valarie .A \& Bitner. J. 2000. Services Marketing: Integrating Customer Focus Across The Firm. Second Edition Hill. . New York: McGraw 